\title{
Hyperglycaemia and reduced glucokinase expression in weanling offspring from dams maintained on a high-fat diet
}

\author{
Marlon E. Cerf ${ }^{1,2 *}$, Christo J. Muller ${ }^{2}$, Don F. Du Toit ${ }^{2}$, Johan Louw ${ }^{1}$ and Sonia A. Wolfe-Coote \\ ${ }^{1}$ Diabetes Research Group, Medical Research Council, Tygerberg, South Africa \\ ${ }^{2}$ Department of Anatomy and Histology, University of Stellenbosch, Tygerberg, South Africa
}

(Received 7 April 2005 - Revised 27 September 2005 - Accepted 27 September 2005)

\begin{abstract}
High-fat feeding reduces the expression of GLUT-2 and the glycolytic enzyme glucokinase (GK). The transcription factor, pancreatic duodenal homeobox-1 (Pdx-1), is important for $\beta$-cell maintenance. The aim of the present study was to determine, in weanling Wistar rats, the effect of a maternal high-fat diet (HFD) during defined periods of gestation and lactation, on body weight, circulating glucose and insulin concentrations, and the expression of GLUT-2, GK and Pdx-1. At postnatal day 21, weights were recorded and glucose and insulin concentrations were measured. The expression levels for mRNA were quantified by LightCycler PCR. Pancreatic sections, immunostained for GLUT-2, GK or Pdx-1, were assessed by image analysis. Weanlings from dams fed an HFD throughout gestation were lighter, with heavier weanlings produced from dams fed an HFD throughout gestation and lactation. Both these groups of weanlings were normoglycaemic, all the others being hyperglycaemic. Hypoinsulinaemia was evident in weanlings from dams fed an HFD throughout gestation only and also for either the first week of lactation or throughout lactation. GLUT-2 mRNA expression was reduced and GLUT-2 immunoreactivity was increased in most of the weanlings. GK mRNA expression and immunoreactivity was reduced in most of the offspring. Pdx-1 mRNA expression was increased in weanlings from dams fed an HFD throughout both gestation and lactation and reduced in those from dams only fed a lactational HFD. Normal Pdx-1 immunoreactivity was found in all of the weanlings. A maternal HFD induces hyperglycaemia in weanlings concomitant with reduced GK expression which may compromise $\beta$-cell function.
\end{abstract}

Endocrine pancreas: Glucose transporter-2: Hypoinsulinaemia: Pancreatic duodenal homeobox-1: Type 2 diabetes

Glucose is transported into cells by facilitated diffusion, which involves binding of glucose to glucose transport proteins (Thorens et al. 1988). GLUT-2 has been shown to be localised in rat pancreatic islets, primarily to the microvesicular patterns of $\beta$-cell membranes adjacent to neighbouring endocrine cells (Orci et al. 1990). The high- $\mathrm{K}_{\mathrm{m}}$ glucose-phosphorylating enzyme glucokinase $(\mathrm{GK})$ is expressed in the $\beta$-cells where it regulates pancreatic glucose sensing (Matschinsky, 1996). In the mature $\beta$-cell, GK regulates glucose homeostasis by catalysing the conversion of glucose to glucose-6-phosphate, after glucose is transported into the $\beta$-cell by GLUT-2. Pancreatic duodenal homeobox-1 (Pdx-1), which is expressed in adult $\beta$-cells, regulates the transcription of the insulin (Ohlsson et al. 1993) and GLUT-2 (Waeber et al. 1996) genes. $\mathrm{Pdx}-1$ is considered to be the master regulator of pancreatic development and $\beta$-cell differentiation and is important for $\beta$-cell maintenance (Cerf et al. 2005a). It has a dual role as an inducer of the endocrine lineage from ductal epithelial cells and in the maturation of $\beta$-cells (Hill \& Duvillie, 2000).

A high-fat diet (HFD) has been linked to the development of obesity, insulin resistance and type 2 diabetes (West \& York, 1998; Kim et al. 2000). A long-term (48 weeks) chal- lenge of C57BL/6J mice with an HFD was reported to lead to hyperglycaemia, hyperinsulinaemia, hyperlipidaemia and hyperleptinaemia (Mulder et al. 2000). High-fat feeding of 4-week-old rats, for a period of 10 weeks, has previously been shown to induce hyperglycaemia, reduce insulin concentrations and decrease the expression levels of both GLUT-2 and GK mRNA (Kim et al. 1995). Exposure of isolated rat islets to palmitic acid has been reported to induce a $70 \%$ decrease in Pdx-1 mRNA and protein expression as well as a $40 \%$ decrease in the binding activity of Pdx-1 for its cognate cis-regulatory elements of GLUT-2 and a $65 \%$ decrease for the insulin promoter (Gremlich et al. 1997). The effect of palmitic acid on Pdx-1 was correlated with decreases in GLUT-2 and GK expression both at mRNA and protein level (Gremlich et al. 1997).

The thrifty phenotype hypothesis proposes that poor fetal and infant growth increases the risk of developing impaired glucose tolerance and the metabolic syndrome in adult life (Hales et al. 1991; Hales \& Barker, 1992; Barker et al. 1993). During late gestation and early neonatal life, most $\beta$-cells are formed by neogenesis (Eriksson \& Swenne, 1982; Swenne \& Eriksson, 1982; Bouwens et al. 1994; Kaung, 1994; Upchurch et al. 1994). It

Abbreviations: GK, glucokinase; HFD, high-fat diet; NGS, normal goat serum; PBGD, porphobilinogen deaminase; Pdx-1, pancreatic duodenal homeobox-1; TBS, tri(hydroxymethyl)-aminomethane-buffered saline.

* Corresponding author: Dr Marlon E. Cerf, fax +27 21938 0456, email marlon.cerf@mrc.ac.za 
has also more recently been suggested that the lactation period may be critical for metabolic programming in offspring from dams fed a low-protein diet (Heywood et al. 2004). It was decided, therefore, in the present study, to investigate the effect of a maternal HFD on body weight, circulating glucose and insulin concentrations and on the expression of GLUT-2, GK and Pdx-1 in weanling offspring.

\section{Methods and materials}

\section{Animals and research design}

Animals were maintained as previously described (Cerf et al. $2005 b$ ). Pregnant rats were fed an HFD for defined periods of gestation and/or lactation, and after lactation, their 3-week-old weanling offspring were studied. The experimental groups consisted of weanlings from dams fed an HFD throughout gestation only (HF-G), throughout gestation and for either lactation week $1(\mathrm{HF}-\mathrm{G}+\mathrm{L} 1)$, or week $2(\mathrm{HF}-\mathrm{G}+\mathrm{L} 2)$, or week 3 $(\mathrm{HF}-\mathrm{G}+\mathrm{L} 3)$, or for all 3 weeks of lactation $(\mathrm{HF}-\mathrm{G}+\mathrm{L})$. A final group of weanlings was from dams fed an HFD throughout lactation only (HF-L). The control group was represented by offspring from dams maintained on a standard laboratory diet throughout both gestation and lactation. The standard laboratory diet $(10.92 \mathrm{~kJ} / \mathrm{g})$ comprised $10 \%$ fat, $15 \%$ protein and $75 \%$ carbohydrate while the HFD $(8.65 \mathrm{~kJ} / \mathrm{g})$ contained $40 \%$ fat (as energy, mostly derived from saturated animal fat), $14 \%$ protein and $46 \%$ carbohydrate. At postnatal day 21, each of the pups was weighed and anaesthetised by intraperitoneal injection with $0.1 \mathrm{ml}$ ketamine hydrochloride $(10 \mathrm{mg} /$ ml; Parke-Med, Cape Town, South Africa). Circulating glucose and insulin concentrations were measured and pancreatic tissue was excised and either snap-frozen, in liquid $\mathrm{N}_{2}$, for storage at $-80^{\circ} \mathrm{C}$ for LightCycler PCR or formalin-fixed for immunohistochemistry and image analysis.

\section{Circulating glucose and insulin concentrations}

Blood glucose concentrations were measured with a glucometer (Precision QID; MediSense Inc., Abingdon, Oxfordshire, UK) and the serum insulin concentrations were determined using a Rat Insulin RIA kit (Linco Research Inc., St Charles, MO, USA).

\section{LightCycler polymerase chain reaction}

RNA was isolated from $21 \mathrm{~d}$ old weanling pancreata (ten per group) using an RNeasy Mini Kit (Qiagen $\mathrm{GmbH}$, Hilden, Germany). cDNA was synthesised from RNA isolated from the pancreata (First Strand cDNA synthesis kit AMV; Roche Diagnostics GmgH, Penzberg, Germany) and used for the subsequent RT-PCR experiments. Primers were designed, using the Primer3 (2005) website, and were produced and purified by PAGE-HPLC (IDT, Coralville, IA, USA). The primer sequences were as follows:

GLUT-2 forward: $5^{\prime}$ - cag tgg agc gtg aag aca aa $-3^{\prime}$;

GLUT-2 reverse: $5^{\prime}$ - agg gaa gga gaa ggt gaa gc $-3^{\prime}$;

GK forward: $5^{\prime}$ - cag tgg agc gtg aag aca aa $-3^{\prime}$;

GK reverse: $5^{\prime}-$ agg gaa gga gaa ggt gaa gc $-3^{\prime}$;

Pdx-1 forward: $5^{\prime}$ - get gga get gga gaa gga at $-3^{\prime}$;

Pdx-1 reverse: $5^{\prime}-$ cgt tgt ccc get act acg $t \mathrm{tt}-3^{\prime}$.
Porphobilinogen deaminase (PBGD), one of the LightCycler housekeeping genes recommended by the manufacturer, is expressed in a broad range of tissues (Grandchamp et al. 1987 ) at a relatively stable expression level and has no known pseudogenes:

PBGD forward: $5^{\prime}-$ gca tac aga ccg aca ctg tgg $-3^{\prime}$;

PBGD reverse: $5^{\prime}$ - ctc tgg caa ggt ttc cag gg $-3^{\prime}$.

PCR products were detected using SYBR green (Stratagene, Amsterdam, The Netherlands). Relative quantification of the genes was done after LightCycler PCR using the RelQuant software (Roche Diagnostics, Mannheim, Germany). Normalisation was achieved using PBGD as a reference against the expression level of the genes investigated. The mRNA expression of the control group was taken as 1, with sample readings $>1$ indicative of overexpression and $<1$ representing underexpression of a particular gene.

\section{Immunohistochemistry}

Slides of serial sections were transferred to $50 \mathrm{~mm}$-tri(hydroxymethyl)-aminomethane-buffered saline (TBS), $\mathrm{pH} 7 \cdot 4$, in a staining jar and were immunostained using avidin D-biotinylated horseradish H complex (Vectastain; Vector Laboratories Inc., Burlingame, CA, USA). The sections (six per group) were incubated in $0.228 \%$ periodic acid in distilled water for $5 \mathrm{~min}$ followed by washing for $10 \mathrm{~min}$ in TBS and incubation in 1:20 diluted normal goat serum (NGS) for $20 \mathrm{~min}$. The primary antibody (to GLUT-2, GK or Pdx-1) was then applied to the sections for either $30 \mathrm{~min}$ (GLUT-2) or overnight (GK and Pdx-1). After washing the sections in TBS for $10 \mathrm{~min}$, rabbit biotinylated antibody (Vectastain) was added for $30 \mathrm{~min}$, followed by another $10 \mathrm{~min}$ wash in TBS. The sections were then incubated in avidin D-biotinylated horseradish H complex (Vectastain) for $60 \mathrm{~min}$. The peroxidase marker was revealed by incubating the sections for 5 min in a $0.05 \%$ enzyme substrate solution of diaminobenzidine tetrachloride (DAB; Sigma, St Louis, MO, USA) containing $0.01 \% \quad \mathrm{H}_{2} \mathrm{O}_{2}$. The sections were counterstained in haematoxylin for $1 \mathrm{~min}$. Method controls involved replacement of the primary antiserum with NGS.

The above protocol was standardised for GLUT-2 where 1:100 rabbit anti-rat GLUT-2 (WAK-Chemie, Bad Soden, Germany) was applied for $30 \mathrm{~min}$ as the primary antibody. For immunolabelling with GK (1:1000; kindly donated by Dr H. Vertigan, CVGI Discovery Department, AstraZeneca, Cheshire, UK) and Pdx-1 (1:1500; a kind gift from Professor C. Wright, Department of Cell Biology, Vanderbilt University Medical Center, Nashville, TN, USA) the protocol was repeated with an additional step of microwaving the slides for $20 \mathrm{~min}$ and allowing them to cool to room temperature before applying NGS. Diaminobenzidine tetrachloride was added for only $2 \mathrm{~min}$.

\section{Image analysis}

Immunolabelled sections were viewed on a Zeiss Axioskop2 light microscope (Carl Zeiss, Jena, Germany) linked to a Zeiss Axiocam digital camera system (Carl Zeiss). Captured micrographs of the islets of Langerhans were morphometrically analysed using the Zeiss KS 300 release 3.0 image anal- 
ysis software (Carl Zeiss Vision, Hallbergmoos, Germany). Data were exported to MS Excel 97 (Microsoft Corp., Bellevue, WA, USA) and statistically analysed using the Statistica package version $6 \cdot 1$ (Statsoft Inc., Tulsa, OK, USA). Assuming areas labelled for GLUT-2, GK or Pdx-1 represent a measure of the content of each factor in pancreatic sections, all of the pancreas sections were scanned for antibody activity (GLUT-2, GK or Pdx-1 immunoreactivity). The areas labelled for each antigen on each section were then added together and expressed as a percentage of the total islet area measured in that section. An average of the areas immunolabelled for each antigen (GLUT-2 or GK or Pdx-1) in the control sections was taken to equal 1. Similarly, an average of the areas of antigen in each experimental group was calculated and expressed as a ratio of the control areas.

\section{Statistical analysis}

The data of each group were compared with the control data and reported as means with their standard errors. Comparisons between the groups were analysed using ANOVA followed by Bonferroni's multiple comparisons for significant tests. Significance was established at $P<0 \cdot 05$.

\section{Results}

Weight, glucose and insulin concentrations

HF-G weanlings had lower body weights, while HF-G $+\mathrm{L}$ weanlings were heavier compared with the control weanlings (Table 1). No differences were found in the body weights of the other weanlings. Apart from the HF-G and HF-G $+\mathrm{L}$ weanlings, which displayed normal glucose levels, hyperglycaemia was evident in all of the weanlings of the other groups (Table 1). HF-G, HF-G + L1 and HF-G + L weanl-

Table 1. Body weight, and circulating glucose and insulin concentrations in weanlings from dams fed a high-fat (HF) diet $†$

(Mean values with their standard errors)

\begin{tabular}{|c|c|c|c|c|c|c|}
\hline & \multicolumn{2}{|c|}{ Weight $(g) \ddagger$} & \multicolumn{2}{|c|}{$\begin{array}{l}\text { Blood glucose } \\
\text { concentration } \\
(\mathrm{mmol} / \mathrm{l}) \S\end{array}$} & \multicolumn{2}{|c|}{$\begin{array}{l}\text { Serum insulin } \\
\text { concentration } \\
\text { (pM)\| }\end{array}$} \\
\hline & Mean & SEM & Mean & SEM & Mean & SEM \\
\hline Control & $37 \cdot 0$ & $1 \cdot 32$ & $4 \cdot 21$ & 0.31 & $219 \cdot 3$ & $49 \cdot 3$ \\
\hline HF-G & $26 \cdot 33^{*}$ & 0.42 & $6 \cdot 26$ & 0.46 & $36 \cdot 37^{*}$ & $12 \cdot 43$ \\
\hline $\mathrm{HF}-\mathrm{G}+\mathrm{L} 1$ & 35.96 & 0.74 & $16 \cdot 92^{*}$ & $1 \cdot 2$ & $135 \cdot 3^{\star}$ & 11.55 \\
\hline $\mathrm{HF}-\mathrm{G}+\mathrm{L} 2$ & 40.04 & 1.09 & $17 \cdot 13^{\star}$ & $1 \cdot 2$ & $252 \cdot 2$ & $25 \cdot 84$ \\
\hline$H F-G+L 3$ & 34.25 & 0.5 & $15 \cdot 30^{*}$ & 1.0 & $223 \cdot 8$ & $21 \cdot 78$ \\
\hline$H F-G+L$ & $47 \cdot 2^{*}$ & 1.08 & $4 \cdot 27$ & 0.1 & $128 \cdot 6^{*}$ & $29 \cdot 3$ \\
\hline HF-L & $35 \cdot 17$ & 0.44 & $12 \cdot 82^{*}$ & 1.0 & $197 \cdot 3$ & $12 \cdot 83$ \\
\hline
\end{tabular}

G, gestation; L, lactation; L1, first week of lactation; L2, second week of lactation; L3, third week of lactation.

*Mean value was significantly different from that for the control group $(P=0.05)$.

† Weanlings were from dams fed an HF diet throughout gestation (HF-G) and for

the first $(H F-G+L 1)$, second $(H F-G+L 2)$ or third $(H F-G+L 3)$ week of lactation, or throughout both gestation and lactation (HF-G $+\mathrm{L}$ ), or only throughout lactation (HF-L). Weanlings in the control group are from dams maintained on a standard laboratory diet throughout both gestation and lactation.

$\ddagger$ Twenty-six to thirty-two weanlings per group.

$\S$ Twenty-four to thirty-two weanlings per group.

|| Twenty to twenty-four weanlings per group. ings were hypoinsulinaemic, with normal circulating insulin concentrations evident in the other weanling groups (Table 1).

\section{Glucose transporter-2 mRNA expression and immunoreactivity}

Apart from HF-G weanlings, where no significant differences in GLUT-2 mRNA expression was found, GLUT-2 mRNA expression was reduced at least 25 -fold in all of the weanlings (Table 2). In contrast, GLUT-2 immunoreactivity was increased approximately 4-fold in all of the weanlings (Table 2).

\section{Glucokinase mRNA expression and immunoreactivity}

Apart from HF-G and HF-G + L1 weanlings, GK mRNA expression was reduced 1.6- to 4-fold in all of the weanlings (Table 2). GK immunoreactivity was reduced 1.6- to 1.9fold in all of the weanlings, except for HF-G and HF-L weanlings, which displayed normal immunoreactivity for GK (Table 2).

\section{Pancreatic duodenal homeobox-1 mRNA expression and immunoreactivity}

Pdx-1 mRNA expression was 11-fold higher in HF-G + L weanlings, with a $3 \cdot 5$-fold in reduction in HF-L weanlings (Table 2). The expression profiles for Pdx-1 mRNA in remaining weanling groups were normal. Normal levels of Pdx-1 immunoreactivity were found in all of the weanlings (Table 2).

\section{Discussion}

The present study reports the effects of an HFD on $\beta$-cell function in relation to the expression profiles of key $\beta$-cell genes in weanling offspring from dams maintained on an HFD. Hyperglycaemia has been suggested to be the causative factor for the deterioration of $\beta$-cell function and the resulting loss of insulin secretory capacity and reduced GK immunoreactivity in the sand rat (Psammomys obesus) maintained on a high-energy diet (Jorns et al. 2002). In the present study, hyperglycaemia was present in weanlings with both reduced and normal circulating insulin concentrations. However, in HF-G + L1 weanlings, hypoinsulinaemia understandably contributes to the hyperglycaemic state. In HF-G + L2, HF$\mathrm{G}+\mathrm{L} 3$ and HF-L weanlings, hyperglycaemia arises despite normal insulin levels. Furthermore, exposure to a maternal HFD, during lactation only, was sufficient to induce hyperglycaemia in weanling offspring. What these low or normal insulin concentrations, in the face of hyperglycaemia, show, is the inability of the animals, at this stage, to restore glucose homeostasis. Insulin resistance, with accompanying hyperglycaemia, induces hypersecretion of insulin from the $\beta$-cells, resulting in hyperinsulinaemia, and an impairment of this adaptation has already been suggested to result in the development of type 2 diabetes (Porte, 1991; Kahn et al. 1993). Interestingly, in the present study, there is the absence of hyperinsulinaemia in the hyperglycaemic weanlings and this may represent an inability to effect this adaptation to correct the hyperglycaemia observed after the HFD challenge. 
Table 2. Gene expression and immunoreactivity for glucose transporter-2, glucokinase (GK) and pancreatic duodenal homeobox-1 (Pdx-1) in weanlings from dams fed a high-fat (HF) diet†

(Mean values with their standard errors)

\begin{tabular}{|c|c|c|c|c|c|c|c|c|c|c|c|c|}
\hline & \multicolumn{2}{|c|}{ GLUT-2 mRNA $\ddagger$} & \multicolumn{2}{|c|}{$\begin{array}{l}\text { GLUT-2 immuno- } \\
\text { reactivity§ }\end{array}$} & \multicolumn{2}{|c|}{ GK mRNA } & \multicolumn{2}{|c|}{$\begin{array}{l}\text { GK immuno- } \\
\text { reactivity§ }\end{array}$} & \multicolumn{2}{|c|}{ Pdx-1 mRNA $\ddagger$} & \multicolumn{2}{|c|}{$\begin{array}{l}\text { Pdx-1 immuno- } \\
\text { reactivity§ }\end{array}$} \\
\hline & Mean & SEM & Mean & SEM & Mean & SEM & Mean & SEM & Mean & SEM & Mean & SEM \\
\hline Control & 1 & 0.467 & 1 & 0.475 & 1 & $0 \cdot 120$ & 1 & 0.071 & 1 & 0.284 & 1 & 0.068 \\
\hline HF-G & 0.585 & 0.295 & $4.418^{*}$ & 0.550 & 0.835 & 0.135 & 0.981 & 0.071 & $1 \cdot 206$ & 0.454 & 1.075 & 0.088 \\
\hline HF-G + L1 & $0.042^{*}$ & 0.016 & $4.783^{*}$ & 0.667 & $1 \cdot 231$ & 0.074 & $0.523^{*}$ & 0.083 & $1 \cdot 870$ & 0.829 & $1 \cdot 126$ & 0.115 \\
\hline $\mathrm{HF}-\mathrm{G}+\mathrm{L} 2$ & $0 \cdot 010^{\star}$ & 0.006 & $4.426^{*}$ & 0.589 & $0.601^{*}$ & 0.134 & $0.564^{*}$ & 0.054 & $1 \cdot 105$ & 0.293 & 1.012 & 0.153 \\
\hline$H F-G+L$ & $0.022^{*}$ & 0.008 & $4 \cdot 289^{\star}$ & 1.054 & $0.390^{*}$ & 0.052 & $0.583^{*}$ & 0.082 & $11 \cdot 344^{*}$ & 3.879 & 1.009 & 0.204 \\
\hline HF-L & $0.006^{\star}$ & 0.003 & $4 \cdot 234^{*}$ & 0.297 & $0.253^{\star}$ & 0.019 & $0 \cdot 881$ & 0.074 & $0 \cdot 286^{\star}$ & 0.098 & 1.075 & 0.103 \\
\hline
\end{tabular}

G, gestation; L, lactation; L1, first week of lactation; L2, second week of lactation; L3, third week of lactation.

*Mean value was significantly different from that for the control group $(P=0.05)$.

† Weanlings were from dams fed an HF diet throughout gestation (HF-G) and for the first (HF-G + L1), second (HF-G + L2) or third (HF-G + L3) week of lactation, or throughout both gestation and lactation (HF-G $+\mathrm{L}$ ), or only throughout lactation (HF-L). Weanlings in the control group are from dams maintained on a standard laboratory diet throughout both gestation and lactation.

$\ddagger$ Ten weanlings per group.

$\S$ Six weanlings per group.

The reduced expression of the key $\beta$-cell enzyme, GK, may also contribute to this inability to adapt and correct the resulting hyperglycaemia.

Interestingly, HF-G $+\mathrm{L}$ weanlings were found to have normal blood glucose concentrations, and this could possibly be related to exposure of the HFD throughout gestation and in the three postnatal weeks, unlike the dietary switch that occurred in the other experimental groups. This persistent HFD exposure may have programmed these progeny to adapt to the diet and therefore confer the ability to maintain glucose homeostasis. Studies in adult rats have shown that high-fat feeding resulted in increased glucose concentrations, reduced insulin concentrations and induced insulin resistance (Kim et al. 1995; Ahren et al. 1999). Although glucose levels were normal in HF-G $+\mathrm{L}$ weanlings, the HFD had induced hypoinsulinaemia. Interestingly, in age $28 \mathrm{~d}$ male Wistar rats fed a low-protein diet for 8 weeks, there was a significant reduction in insulinaemia, but glycaemia was unaltered (Delghingaro-Augusto et al. 2004), as was found in our $\mathrm{HF}-\mathrm{G}+\mathrm{L}$ weanlings. We postulate that, if $\mathrm{HF}-\mathrm{G}+\mathrm{L}$ weanlings had been maintained for a longer term on an HFD, they may eventually have reached a point of saturation and become hyperglycaemic.

Similar to HF-G $+\mathrm{L}$ weanlings, normoglycaemia was accompanied by hypoinsulinaemia in HF-G weanlings. In a study on offspring from dams fed a low-protein diet during gestation, then a normal diet after weaning, blood glucose concentrations were normal at age $28 \mathrm{~d}$, with reduced blood insulin concentrations and reduced volume density of the endocrine pancreas (Dahri et al. 1991). Another study reported that weanlings exposed to a low-protein diet had lower body weights, with normal serum glucose levels and reduced serum insulin levels (Latorraca et al. 1998). In HF-G weanlings, GLUT-2 mRNA expression, and both GK and Pdx-1 mRNA expression and immunoreactivity were normal. This appears to ensure normoglycaemia, but the HFD intervention, during gestation only, is sufficient to induce hypoinsulinaemia. In the HF-G $+\mathrm{L}$ weanlings, however, GLUT-2 mRNA expression and both GK mRNA expression and immunoreactivity is reduced. This suggests that intervention with a low-fat-diet, during lactation, a critical window of development, leads to the recovery of some $\beta$-cell function.

In isolated $\beta$-cells, the responsiveness of the individual $\beta$-cell is determined by the function of its glucose recognition apparatus (Heimberg et al. 1996; Ling et al. 1996). In most of the weanlings, hyperglycaemia was accompanied by impaired GK expression. The ability of insulin to be secreted in response to glucose would be dependent, in part, on the ability of GK to metabolise glucose. Reduced GK expression, as found in most of our weanlings, may well then compromise $\beta$-cell function. A recent study reported that weanling rats from dams maintained on a low-protein diet, throughout gestation and weaning, displayed reduced insulin secretion and a reduction in the $K_{m}$ value and protein expression for GK (determined by Western blotting) (Heywood et al. 2004). We have now shown that weanlings from dams fed an HFD throughout both gestation and lactation (HF-G + L weanlings) had reduced GK mRNA and protein expression (determined by immunohistochemical analysis). The present study therefore supports the hypothesis that nutrition during the critical periods of development, such as in utero and during lactation, programmes certain metabolic processes to adapt to this particular level of nutrition throughout life (Hales \& Barker, 1992).

A study showed no increase in body weight in rats after 2 weeks of high-fat feeding, but an increase after 4 and 8 weeks (Ahren et al. 1999). In the present study, HF-G $+\mathrm{L}$ weanlings, exposed to an HFD throughout both gestation and lactation for a total period of 6 weeks, were significantly heavier. In contrast, the other weanlings had normal or reduced body weights after exposure to a maternal HFD for $3-4$ weeks. This suggests that a longer term of HFD challenge is required to induce a significant weight gain. The lower body weights in the HF-G weanlings may be attributed to the dietary switch of their mothers that were first fed an HFD during gestation, then a standard laboratory (low-fat) diet throughout lactation. The dams have a preference for the HFD (Cerf et al. 2005); therefore they consumed a reduced amount of nutrients during lactation which may have a role in the compromised growth of their offspring. Another factor contributing to the 
low body weights is the hypoinsulinaemia evident in the HF-G weanlings, as insulin is an important growth factor (Fowden, 1993).

In most of the weanlings, both Pdx-1 mRNA expression (which only differed in HF-G $+\mathrm{L}$ and HF-L weanlings) and immunoreactivity were relatively normal, displaying the ability of the animals to maintain adequate expression of this key transcription factor despite the HFD challenge. However, GLUT-2 was underexpressed at mRNA level, but overexpressed at protein level in all of the weanlings studied, which shows the differential effect of the HFD treatment on the expression of GLUT-2 mRNA and protein expression. Some studies have reported no correlation between mRNA and protein expression in several genes, suggesting the importance of post-translational mechanisms controlling gene expression (Gygi et al. 1999; Gorovits et al. 2003). The metabolic milieu, i.e. HFD-induced hyperglycaemia, may affect translational and/or post-translational processing or the stability of GLUT-2 may be increased in a diabetic state as suggested for GLUT-8 protein regulation (Gorovits et al. 2003).

\section{Conclusions}

An HFD induced significant changes in circulating glucose and insulin concentrations and in the expression of the glucose-sensing genes, GLUT-2 and GK, while Pdx-1 expression was least affected. This suggests that metabolic changes are taking place enabling the animal to adapt physiologically in order to maintain glucose homeostasis after the HFD challenge. Hyperglycaemia was found to be accompanied by reduced GK expression, suggesting a role of this glycolytic enzyme in the declining $\beta$-cell function.

\section{Acknowledgements}

The authors are grateful to Mrs C. Chapman for the immunolabelling experiments, Dr L. Du Plessis for assistance with the molecular biology experiments, Professor S. Maritz for statistical analysis, and to Dr H. Vertigan and Professor C. Wright for kindly donating antibodies.

\section{References}

Ahren B, Gudbjartsson T, Al-Amin AN, Martensson H, MyrsenAxcrona U, Karlsson S, Mulder H \& Sundler F (1999) Islet perturbations in rats fed a high-fat diet. Pancreas 18, 75-83.

Barker DJ, Hales CN, Fall CH, Osmond C, Phipps K \& Clark PM (1993) Type 2 (non-insulin-dependent) diabetes mellitus, hypertension and hyperlipidaemia (syndrome $\mathrm{X}$ ): relation to reduced fetal growth. Diabetologia 36, 62-67.

Bouwens L, Wang RN, De Blay E, Pipeleers DG \& Kloppel G (1994) Cytokeratins as markers of ductal cell differentiation and islet neogenesis in the neonatal rat pancreas. Diabetes 43, 1279-1283.

Cerf ME, Muller CJ, Du Toit DF, Louw J \& Wolfe-Coote SA (2005a) Transcription factors, pancreatic development, and beta-cell maintenance. Biochem Biophys Res Commun 326, 699-702.

Cerf ME, Williams K, Nkomo XI, Muller CJ, Du Toit DF, Louw J \& Wolfe-Coote SA (2005b) Islet cell response in the neonatal rat after exposure to a high-fat diet during pregnancy. Am J Physiol 288, R1122-R1128.
Dahri S, Snoeck A, Reusens-Billen B, Remacle C \& Hoet JJ (1991) Islet function in offspring of mothers on low-protein diet during gestation. Diabetes 40, Suppl. 2, 115-120.

Delghingaro-Augusto V, Ferreira F, Bordin S, do Amaral ME, Toyama MH, Boschero AC \& Carneiro EM (2004) A low protein diet alters gene expression in rat pancreatic islets. J Nutr 134, $321-327$.

Eriksson U \& Swenne I (1982) Diabetes in pregnancy: growth of the fetal pancreatic B cells in the rat. Biol Neonate 42, 239-248.

Fowden AL (1993) Insulin deficiency: effects on fetal growth and development. J Paediatr Child Health 29, 6-11.

Gorovits N, Cui L, Busik JV, Ranalletta M, Hauguel de-Mouzon S \& Charron MJ (2003) Regulation of hepatic GLUT8 expression in normal and diabetic models. Endocrinology 144, 1703-1711.

Grandchamp B, De Verneuil H, Beaumont C, Chretien S, Walter O \& Nordmann Y (1987) Tissue-specific expression of porphobilinogen deaminase. Two isoenzymes from a single gene. Eur J Biochem 162, 105-110.

Gremlich S, Bonny C, Waeber G \& Thorens B (1997) Fatty acids decrease IDX-1 expression in rat pancreatic islets and reduce GLUT2, glucokinase, insulin, and somatostatin levels. J Biol Chem 272, 30261-30269.

Gygi SP, Rochon Y, Franza BR \& Aebersold R (1999) Correlation between protein and mRNA abundance in yeast. Mol Cell Biol 19, 1720-1730.

Hales CN \& Barker DJ (1992) Type 2 (non-insulin-dependent) diabetes mellitus: the thrifty phenotype hypothesis. Diabetologia 35 , 595-601.

Hales CN, Barker DJ, Clark PM, Cox LJ, Fall C, Osmond C \& Winter PD (1991) Fetal and infant growth and impaired glucose tolerance at age 64. BMJ 303, 1019-1022.

Heimberg H, De Vos A, Moens K, Quartier E, Bouwens L, Pipeleers D, van Schaftingen E, Madsen O \& Schuit F (1996) The glucose sensor protein glucokinase is expressed in glucagon-producing alpha-cells. Proc Natl Acad Sci U S A 93, 7036-7041.

Heywood WE, Mian N, Milla PJ \& Lindley KJ (2004) Programming of defective rat pancreatic beta-cell function in offspring from mothers fed a low-protein diet during gestation and the suckling periods. Clin Sci (Lond) 107, 37-45.

Hill DJ \& Duvillie B (2000) Pancreatic development and adult diabetes. Pediatr Res 48, 269-274.

Jorns A, Tiedge M, Ziv E, Shafrir E \& Lenzen S (2002) Gradual loss of pancreatic beta-cell insulin, glucokinase and GLUT2 glucose transporter immunoreactivities during the time course of nutritionally induced type-2 diabetes in Psammomys obesus (sand rat). Virchows Arch 440, 63-69.

Kahn SE, Prigeon RL, McCulloch DK, et al. (1993) Quantification of the relationship between insulin sensitivity and beta-cell function in human subjects. Evidence for a hyperbolic function. Diabetes 42, $1663-1672$.

Kaung HL (1994) Growth dynamics of pancreatic islet cell populations during fetal and neonatal development of the rat. Dev Dyn 200, 163-175.

Kim CH, Youn JH, Park JY, Hong SK, Park KS, Park SW, Suh KI \& Lee KU (2000) Effects of high-fat diet and exercise training on intracellular glucose metabolism in rats. Am J Physiol 278, E977-E984.

Kim Y, Iwashita S, Tamura T, Tokuyama K \& Suzuki M (1995) Effect of high-fat diet on the gene expression of pancreatic GLUT2 and glucokinase in rats. Biochem Biophys Res Commun 208, $1092-1098$.

Latorraca MQ, Carneiro EM, Boschero AC \& Mello MA (1998) Protein deficiency during pregnancy and lactation impairs glucoseinduced insulin secretion but increases the sensitivity to insulin in weaned rats. Br J Nutr 80, 291-297.

Ling Z, Kiekens R, Mahler T, Schuit FC, Pipeleers-Marichal M, Sener A, Kloppel G, Malaisse WJ \& Pipeleers DG (1996) Effects 
of chronically elevated glucose levels on the functional properties of rat pancreatic beta-cells. Diabetes 45, 1774-1782.

Matschinsky FM (1996) Banting Lecture 1995. A lesson in metabolic regulation inspired by the glucokinase glucose sensor paradigm. Diabetes 45, 223-241.

Mulder H, Martensson H, Sundler F \& Ahren B (2000) Differential changes in islet amyloid polypeptide (amylin) and insulin mRNA expression after high-fat diet-induced insulin resistance in C57BL/6J mice. Metabolism 49, 1518-1522.

Ohlsson H, Karlsson K \& Edlund T (1993) IPF1, a homeodomain-containing transactivator of the insulin gene. EMBO J 12, 4251-4259.

Orci L, Ravazzola M, Baetens D, Inman L, Amherdt M, Peterson RG, Newgard CB, Johnson JH \& Unger RH (1990) Evidence that down-regulation of beta-cell glucose transporters in non-insulindependent diabetes may be the cause of diabetic hyperglycemia. Proc Natl Acad Sci U S A 87, 9953-9957.

Porte D Jr (1991) Banting Lecture 1990. Beta-cells in type II diabetes mellitus. Diabetes 40, 166-180.
Primer3 (2005). Primer3 Input. http://frodo.wi.mit.edu/cgi-bin/ primer3/primer3_www.cgi.

Swenne I \& Eriksson U (1982) Diabetes in pregnancy: islet cell proliferation in the fetal rat pancreas. Diabetologia 23, 525-528.

Thorens B, Sarkar HK, Kaback HR \& Lodish HF (1988) Cloning and functional expression in bacteria of a novel glucose transporter present in liver, intestine, kidney, and beta-pancreatic islet cells. Cell 55, 281-290.

Upchurch BH, Aponte GW \& Leiter AB (1994) Expression of peptide $\mathrm{YY}$ in all four islet cell types in the developing mouse pancreas suggests a common peptide YY-producing progenitor. Development 120, 245-252.

Waeber G, Thompson N, Nicod P \& Bonny C (1996) Transcriptional activation of the GLUT2 gene by the IPF-1/STF-1/IDX-1 homeobox factor. Mol Endocrinol 10, 1327-1334.

West DB \& York B (1998) Dietary fat, genetic predisposition, and obesity: lessons from animal models. Am J Clin Nutr 67, 505S-512S. 